\title{
Application of Internet of Things in International Land Port Logistics
}

\section{Development}

\author{
Wang Huizhen \\ (Xi'an International University ,Xi'an Shaanxi in China,710077)
}

Key words: Internet of things; International Land Port; Intellectual Logistics

\begin{abstract}
The development of Internet of things has been listed as "12th Five-Year" planning, the development of logistics industry has become an important symbol of a country's comprehensive strength and scientific and technological level.The Internet of Things is one of the important strategies in today's world, a new round of economic growth and the development of science and technology, International land Port as a typical modern logistics service industry agglomeration platform, become an important model for the development of export-oriented economy in inland areas in recent years. A combination of things with the development is not only the integration of advanced information technology and logistics industry, promote the development of more International Land Port the representative of the modern service industry into a powerful driving force, but also brings a new opportunity for the development of International Land Port "wisdom".
\end{abstract}

\section{Internet of things}

The Internet of things (Internet of Things), refers to various information sensing devices such as radio frequency identification (RFID) a huge network device, infrared sensors, global positioning systems, laser scanners and various other devices and the Internet combine. "Internet of things" is the English name of the Internet of things, abbreviated as IOT. As the name suggests, the Internet of things can be called the Internet of things connected". So things have two meanings: First, in essence, the Internet is a kind of based on Internet ubiquitous network, its core is currently widely used in Internet, and on the basis of the Internet to further extend and expand to achieve full interoperability; Second, with communication function between objects, objects and objects of information exchange and transmission, automatic identification and physical communication. In order to domain specific, things are often more narrowly understood as: the Internet of things is based on electronic label and EPC, the real Internet based on the Internet, its purpose is to achieve interoperability and real-time sharing of global information items.

\section{Key Technologies of the Internet of Things}

(1) two-dimensional code

The two-dimensional code is a particular geometry according to certain rules in the plane (2D) distribution of black and white graphics data symbol information; in coding, the clever use of a computer-based internal logic " 0 " and "1" bit stream concept, using a plurality of corresponding binary the geometry to represent the text value of information, through the image input device or optical scanning equipment automatic recognition to achieve automatic information processing: $2 \mathrm{D}$ 
barcode / two-dimensional code can express the information in two horizontal and vertical orientation, so it can express a large amount of information in a small area.Two dimensional code technology originated in the late 1980s, the two-dimensional code has been a very mature technology, has been widely used in many countries. At present, the global one-dimensional code, two-dimensional code of the code system up to more than 250 kinds, including the common PDF417, QRCode, DM, etc., many of the code system to the most widely used DM code. DM code originated in 1989, including NASA, USDOD two standards, DM is characterized by the use of error correcting code complexity, the code has strong anti pollution capability, the DM code is on the Korean market, the mainstream of system code, DM code is also used in China and Fujian mobile jointly operate the new continent's wing project code. QR code is a successful development of the Japanese DENSO company in 1994, this code system is characterized by efficient representation of Chinese characters, is currently the mainstream Japanese two-dimensional code technical standards.

(2) RFID Technology

Radio frequency identification (Radio Frequeney ldentifieatson) (hereinafter referred to as RFID) is a non-contact automatic identification technology in 1990s began to rise, its basic principle is to use radio signals through space coupling to achieve non-contact transmission of information, and through the message to identify the purpose. It is a way of using RF non-contact automatic identification technology of two-way communication, multi object recognition, non-contact identification, object recognition, high anti-interference ability, have the relevant characteristics of durability, demonstrates the great potential of development, the development of information technology is one of the most promising twenty-first Century.

(3) EPC network technology

The logistics management system of RFID electronic tag is through the Internet of things (EPC Network) system, networking system is much higher than the intelligent degree of the traditional logistics management, it can carry out a full range of management and flow of all the items in the world through the Internet on the ONS server and PML server.

(4) GPS Technology

GPS global positioning system (Global Positioning System GPS) is the United States began to develop from the last century in 70s, lasted for 20 years at a cost of \$20 billion in March 1994 to complete the overall deployment, to achieve its all-weather, high precision and global coverage. Today, GPS and modern communication technology combined with the method of determination of three-dimensional coordinates of the earth's surface from static to dynamic data postprocessing, and real-time positioning and navigation, greatly expand the breadth and depth of its application. Carrier phase difference method GPS technology can greatly improve the relative positioning accuracy. In a small range can reach centimeter precision. In addition, due to the GPS measurement technology of measuring points between the visibility and geometric aspects of requirements than the conventional measuring method is flexible and convenient to have can be used to measure various levels of control network. GPS total station of anti - Exhibition in terrain and ground measurement and a variety of engineering, deformation, surface subsidence monitoring has been widely used in precision, efficiency, cost and other aspects show great superiority.

\section{The application of Internet of things in international port logistics}

International Land Port logistics mode is established in the inland regions, with the port 
function, it is the title of scholars on the existence of differences, names are used frequently in international land port, International Land Port, port, dock, anhydrous dry dry port etc.. According to the seaport and airport name by International Land Port name habits. Generally speaking, the International Land Port is the center of the city in the inland areas of railway, highway interchanges, transportation regulations, in accordance with the relevant international treaties and conventions established by open International Land Port, is located in the inland area of the coastal port feeder port and logistics operation platform, can provide convenient services to the International Land Port inland area.

Since 2000, the theory of port and port was first proposed by scholar Xi Ping of Xi'an Eurasia University. After more than ten years of argumentation and development, it has fully demonstrated its vitality and vitality. Under the influence of international land port and International Land Port area, especially after the construction of Xi'an International Land Port area, inland cities and land border ports also plan to construct land port. Currently, China has operated and is planning the construction of the land port about more than and 50.

International Land Port planning and construction boom, there are also some problems, these problems are reflected in the mainland to Hong Kong as a modern logistics platform, the development of logistics information system of problems for International Land Port operation management based on imperfect logistics service ability is not enough. This also provides a broad space for the Internet of things technology in the operation and management of land port.

\section{the impact of Internet of things technology on international port development}

the relationship between Internet of things and modern logistics

The development of Internet of things technology is the basis and condition to promote the formation and development of logistics industry. Wide application of networking technology in the logistics industry, to promote the rational allocation of resources and optimize the logistics process, the traditional logistics has become a system from production to consumption logistics chain, so as to realize the logistics fast, safe and reliable, low cost.

Logistics information system based on shared data acquisition (such as traffic flow data, the background data), for each participant in the logistics system (such as logistics providers, logistics demand, government and financial institutions) to provide the foundation data, so it is related to logistics, business flow, information flow and capital flow among participants. At present, many advanced modern logistics system has possessed the advanced technical features such as information, digitalization, network, integration, intelligence, flexibility, agility, visualization, automation and so on. A lot of logistics system and the network also uses the latest laser, infrared, wireless, encoding, address recognition, automatic identification, positioning, contactless power supply, optical fiber, sensor, database, RFID, satellite positioning technology, which integrates light, machine, electricity, information technology in one of the new technologies in the integration the application of the logistics system, is actually the embodiment of IOT technology applied in the logistics industry.

Application of Internet of things technology in International Land Port operation

Each land port logistics park by road freight system (highways, railways), land port operating system, Warehouse storage operation system, logistics equipment and other system components. Based on different systems (Systems), they also have their own characteristics, the need for different technical equipment and records of different transport information. These systems include the main processes and links of land port logistics, providing detailed and comprehensive 
information for port regulation and enterprise production.

(1) Land Freight System

Road passenger transport system is responsible for the collection of vehicle information, vehicle identification, pressure sensor mainly adopts speed sensing, GPS tracking, video surveillance technology. The vehicle identification sensor to identify and record the types of transport vehicles, license plate, the company and other relevant information, can facilitate the management and supervision of the owner and query. The pressure velocity sensor can record and transport vehicles and cargo operation data, vehicles are not overweight speeding or non normal parking can be seen at a glance. GPS tracking is mainly the vehicle positioning, in general, in the land transport phase, vehicle positioning and box Bit is unified. Video surveillance is mainly to facilitate the inspection of relevant personnel, especially in the case of customs supervision, video surveillance can facilitate customs inspection.

(2) Highway Port Operation System

Highway port operation system mainly collects the relevant information of the wharf front operation, mainly uses video monitoring, identification sensor, GPS+GIS tracking, automatic sorting technology. At the same time in the video surveillance for the customs and other port departments and park enterprises to provide cutting-edge production, to achieve no blind area regulation of the customs area, and can provide on-site production conditions for the park enterprise control room. Recognition is to identify the relevant information of the sensor box, according to the highway port circadian production plan, on whether the specific needs of each case discharge, in what position of the vehicle is still straight into the library and other information recognition and feedback to the control and bridge crane, truck driver. GPS+GIS tracking dynamic case tracking, query and arrange outbound Trailer convenient consignor. Automatic sorting, based on the identification of sensing information, the computer can automatically add some attributes to the box, improve production efficiency and accuracy.

(3) Storage Yard (Park) Warehouse Operation System

Yard (Park) warehousing operation system can collect information of International Land Port logistics park and park warehouse in the warehouse, the system is mainly used for video surveillance, humidity sensor, thermal sensor, smoke sensor, gas sensor, position sensor technology. Through video surveillance can facilitate shippers and warehouse management personnel to understand the status of goods, especially convenient logistics enterprise management. Humidity, thermal, smoke sensing is mainly for fire prevention considerations, to ensure the safety of the library site, all-weather automatic detection of warehouse environment. Gas sensing is mainly for some goods for air environment requirements are very high, so can use gas sensor report warehouse air some indicators, auxiliary logistics enterprise management. Positioning sensor placed in the goods, reporting goods (boxes) located in the shelves or the location of the yard to facilitate the search.

(4)Logistics Equipment System

Storage yard (yard) warehouse operating system mainly collects all kinds of loading and unloading equipment related information in port area, using torque sensor, video monitoring, identification sensor technology. Torque sensor installed in the loading and unloading equipment, in order to facilitate understanding of cargo weight and handling equipment working state, to ensure the safety of production. Video monitoring and dock front production system video monitoring role is roughly the same. Identification of sensors is mainly to facilitate the loading and unloading 
machinery to identify the correct operation of goods, improve production efficiency and accuracy.

\section{Reference}

[1] Xi Ping. Basic concept and operation of International Land Port of land [J]. China storage and transportation, 2007 (1):71-72.

Lin Ling [2]. Application and construction of Internet of things technology in logistics industry [D], Beijing University of Posts and Telecommunications.2011.5.

[3] Zhang Duo. Internet of things trend [M]. Beijing: Tsinghua University press, 2010

[4] in the container. Tianxiang International Land Port location and transportation mode selection research [D]. Dalian: Dalian Maritime University, 2012

[5] Jiang runner. Research on Internet of things based on EPC Guangdong communication technology [J], Guangdong communication technology.2005.

Author brief introduction: Wang Huizhen (1976 -), female, Pingdingshan, Henan Province, Xi'an International University Business College, Title: Associate Professor, Research Direction: International Land Port logistics, logistics information technology. Contact: 13259915781 284405896@qq.com

From Shaanxi Provincial Social Science Foundation

Project No. of Shaanxi Social Science Foundation; 2015D023 